\title{
Sequential Approach with Matrix Framework for Various Types of Economic Thermal Power Dispatch Problems
}

\author{
Subramanian Srikrishna, Ganesan Sivarajan \\ Department of Electrical Engineering, FEAT, Annamalai University, Annamalainagar, India \\ E-mail:dr_smani@yahoo.co.in,ganeshshriraj@gmail.com \\ Received January 22, 2010; revised February 25, 2010; accepted March 24, 2010
}

\begin{abstract}
This paper presents a sequential approach with matrix framework for solving various kinds of economic dispatch problems. The objective of the economic dispatch problems of electrical power generation is to schedule the committed generating units output so as to meet the required load demand while satisfying the system equality and inequality constraints. This is a maiden approach developed to obtain the optimal dispatches of generating units for all possible load demands of power system in a single execution. The feasibility of the proposed method is demonstrated by solving economic load dispatch problem, combined economic and emission dispatch problem, multiarea economic dispatch problem and economic dispatch problem with multiple fuel options. The proposed methodology is tested with different scale of power systems. The generating unit operational constraints are also considered. The simulation results obtained by proposed methodology for various economic dispatch problems are compared with previous literatures in terms of solution quality. Numerical simulation results indicate an improvement in total cost saving and hence the superiority of the proposed method is also revealed for economic dispatch problems.
\end{abstract}

Keywords: Combined Economic and Emission Dispatch, Composite Cost Function, Economic Dispatch, Multiarea Economic Dispatch, Multiple Fuel Options, Prohibited Operating Zone, Ramp Rate Limits, Sequential Approach, Transmission Loss

\section{Introduction}

The primary objective of the economic dispatch problem is to schedule the generations of thermal units so as to meet the required load demand at minimum operating cost while satisfying the individual and system operating constraints. Traditionally, the cost function for generating units has been approximated as a quadratic function. A variety of optimization techniques has been used for solving economic dispatch problems. The conventional methods include traditional lambda-iteration method, the base point and participation factors method, and the gradient methods are suggested to solve economic dispatch problems [1,2]. The applications of classical methods, such as linear or quadratic programming are also applied for solving economic dispatch problems $[3,4]$.

The methods based on operational research and artificial intelligence concepts such as genetic algorithm, evolutionary algorithms, fuzzy and artificial neural networks have been given attention for solving economic dispatch problems because of their ability to find the solution near global optimal. Simulated Annealing tech- nique (SA) and Genetic Algorithm (GA) have been applied to determine the optimal generation schedule for economic dispatch problem in a power system $[5,6]$. Artificial neural network based models are developed for the solution of economic power dispatch problem $[7,8]$. Particle Swarm Optimization method (PSO) has been applied for solving economic dispatch problems with various operating constraints like prohibited operating zones and ramp rate limits $[9,10]$. Evolutionary strategy based algorithm is suggested for solving economic dispatch problem [11]. A partition approach based solution for economic dispatch problems considering the physical limitations of the system is presented [12]. An enhanced Hopfield neural network model is developed to solve economic dispatch problems [13]. The heuristic search techniques such as Differential Evolution (DE), Chaotic and ant swarm optimization algorithm and Direct Search GA (DSGA) have been applied to solve economic dispatch problems [14-17]. Hybrid approaches including SA-PSO and Bacterial foraging-Nelder Mead method have also been developed to obtain the dispatches of generating units $[18,19]$. 
Due to environmental concerns, Combined Economic and Emission Dispatch (CEED) problem has been formulated to determine the optimal amount of generated power for the generating units in the system by minimizing the fuel cost and emission level simultaneously subject to various system constraints. The passage of clean air act amendments in 1990 has forced utilities to reduce their $\mathrm{SO}_{2}$ and $\mathrm{NOx}$ emissions since both are the primary power plant emissions [20]. A general formulation based on the Lagrange relaxation method is presented for solving environmental constrained economic dispatch problem [21]. Lamount and Qbesses detailed various emission dispatching strategies and solution procedure based on emission shadow prices [22]. Srikrishna and Palanichamy suggested price penalty factor to convert bi objective function into a single objective function [23]. Fuzzy logic and neural network models are developed for solving this multiobjective optimization problem [24-28]. The heuristic search methods are applied to solve this problem [29,30]. Quadratic Programming (QP) method based solution for this multi objective problem is presented [31].

Dynamic programming recursive approach is developed for solving emission constrained economic dispatch problem [32]. L. Wang and C. Singh investigated to solve this problem by applying a fuzzified multi objective particle swarm optimization algorithm [33]. An approach based on constrained pattern search method is presented to solve this problem [34]. Simplified recursive approach is presented for the solution of this multiobjective optimization problem [35]. The authors developed a generalized equation to find the optimal generations of units. Palanichamy and Sundar Babu developed direct method for solving this type of problems based on mathematical modeling [36]. Artificial neural network (ANN), Fuzzy logic based models and heuristic search techniques are used for solving this multiobjective problem [37-40].

The economic dispatch problem of a power system is extended to take into consideration of additional necessary constraints such as transmission capacity limits to ensure security of the system. Direct Search Method (DSM) and ANN models have been suggested for solving the multi area economic dispatch problem [41,42].

In certain fossil fired generating units use different fuels hence the cost function are represented as a segmented piecewise quadratic function. This problem faces with the problem of identification of the most economical fuel of each unit. Lin and Viviani reported Hierarchical Method [HM] to solve the economic dispatch problem with piecewise quadratic functions [43]. Artificial neural network models and heuristic search techniques are used for solve this problem [44-48].

In this article, simplified methodology is presented for solving economic dispatch problems namely, large scale economic dispatch, economic dispatch with operational constraints, combined economic and emission dispatch, multi area economic dispatch and economic dispatch with multiple fuel options. The proposed approach is demonstrated with suitable test systems.

\section{Problem Formulation}

The problem formulation for economic dispatch, combined economic and emission dispatch, multiarea economic dispatch and economic dispatch with multiple fuel options are described as follows.

\subsection{Economic Dispatch (ED) Problem with Generator Operating Constraints}

The objective of economic dispatch is to simultaneously minimize the generation cost rate and to meet the load demand of a power system over some appropriate period while satisfying various operating constraints. The objective function of an economic dispatch problem can be formulated as,

$$
\min F_{T}=\sum_{i=1}^{n} F_{i}\left(P_{i}\right)=\sum_{i=1}^{n} a_{i} P_{i}^{2}+b_{i} P_{i}+c_{i}
$$

Constraints

1) Power balance constraint

$$
\sum_{i=1}^{n} P_{i}=P_{G}=P_{D}+P_{L}
$$

The transmission loss can be expressed as,

$$
P_{L}=\sum_{i=1}^{n} \sum_{j=1}^{n} P_{i} B_{i j} P_{j}+\sum_{i=1}^{n} B_{0 i} P_{i}+B_{00}
$$

or approximately

$$
P_{L}=\sum_{i=1}^{n} \sum_{j=1}^{n} P_{i} B_{i j} P_{j}
$$

2) Generator operational constraints

a. Generator capacity constraint

$$
P_{i, \min } \leq P_{i} \leq P_{i, \max }
$$

\section{b. Ramp rate limits}

The inequality constraints due to ramp rate limits for unit generation changes are given

1) as generation increases

$$
P_{i}-P_{i}^{0} \leq U R_{i}
$$

2) as generation decreases

$$
P_{i}-P_{i}^{0} \leq D R_{i}
$$

The generator operation constraint after including ramp rate limit of generators can be described as,

$$
\max \left(P_{i, \min }, P_{\mathrm{i}}^{0}-D R_{i}\right) \leq P_{i} \leq \min \left(P_{i, \max }, P_{i}^{0}+U R_{i}\right)
$$




\section{c. Prohibited operating zone constraint}

The feasible operating zones of unit $i$ can be described as follows,

$$
\begin{gathered}
P_{i, \min } \leq P_{i} \leq P_{i, l}^{l} \\
P_{i, j-1}^{u} \leq P_{i} \leq P_{i, j}^{l}, \quad j=2,3, \ldots, n_{i} \\
P_{i, n_{i}}^{u} \leq P_{i} \leq P_{i, \max }
\end{gathered}
$$

\subsection{Combined Economic and Emission Dispatch (CEED) Problem}

This problem is formulated by including the reduction of emission as an objective. Like the fuel cost function given in (1), the total emission of generation $\mathrm{E}_{\mathrm{T}}(\mathrm{kg} / \mathrm{h})$ can be expressed by a quadratic function of generation as,

$$
E_{T}=\sum_{i=1}^{n}\left(d_{i} P_{i}^{2}+e_{i} P_{i}+f_{i}\right)
$$

A multi-objective optimization problem is converted in to a single objective optimization problem by introducing price penalty factor $h$ as follows,

$$
F_{T}=\sum_{\mathrm{i}=1}^{\mathrm{n}}\left(a_{i} P_{\mathrm{i}}^{2}+b_{i} P_{i}+c_{i}\right)+h_{i}\left(d_{i} P_{\mathrm{i}}^{2}+e_{i} P_{\mathrm{i}}+f_{i}\right)
$$

and this objective function has to satisfy the power balance constraint and the generation capacity constraints. The price penalty factor that coordinates the emission with the normal fuel cost.

\subsection{Multi Area Economic Dispatch (MAED) Problem}

The objective of multi area economic dispatch is to determine the generation levels and the interchange power between areas that minimize the system operation cost while satisfying a set of constraints as,

$$
\min \sum_{m=1}^{M} F_{m}=\min \sum_{m=1}^{M} \sum_{n=1}^{N_{m}}\left(a_{m n} P_{m n}^{2}+b_{m n} P_{m n}+c_{m n}\right)
$$

Subject to

1) Area power balance constraint

$$
\sum_{m=1}^{N_{m}} P_{m n}+\sum_{j \in \beta_{m}} t_{k j}-\sum_{j \in \beta_{m}} t_{j k}-P_{D M}=0
$$

2) Generation limits constraint

$$
P_{m n, \min } \leq P_{m n} \leq P_{m n, \max }
$$

3) Tie line limits constraint

$$
t_{j k, \min } \leq t_{j k} \leq t_{j k, \max }
$$

\subsection{Economic Dispatch Problem with Multiple Fuel Options (EDMFO)}

In economic dispatch problem, the fuel cost of each generator is represented by a single quadratic cost function. Owing to multiple fuel options, the cost function may become piecewise quadratic. Hence, the economic dispatch problem with piecewise quadratic function is defined as,

$$
\min \sum_{j=1}^{N} F_{j}\left(P_{j}\right)
$$

where,

$$
F_{j}\left(P_{j}\right)=\left\{\begin{array}{l}
a_{j 1} P_{j}^{2}+b_{j 1} P_{j}+c_{j 1}, \text { fuel } 1, P_{j, m i n} \leq P_{j} \leq P_{j 1} \\
a_{j 2} P_{j}^{2}+b_{j 2} P_{j}+c_{j 2}, \text { fuel } 2, P_{j 1} \leq P_{j} \leq P_{j 2} \\
\cdot \\
a_{j m} P_{j}^{2}+b_{j m} P_{j}+c_{j m}, \text { fuel } m, P_{j, m-1} \leq P_{j} \leq P_{j, \max }
\end{array}\right.
$$

This objective function is minimized subject to power balance constraint.

\section{Solution Methodology}

\subsection{Demonstration of Sequential Approach with Matrix Framework}

Sequential approach with matrix framework is proposed for solving economic dispatch problems. This is the first method developed to obtain the optimal dispatches for all possible load demands in a system. The demonstration of the solution methodology is presented in this section.

The electric power production in a power plant is allowed to vary from minimum technical limit $\left(P_{\min }\right)$ to maximum technical limit $\left(P_{\max }\right)$. Initially the $P_{i, \min }$ of all generating units in a power plant are considered as initial state input values and is represented by a single dimensional matrix as,

$$
s=\left[\begin{array}{lll}
P_{1, \min } & P_{2, \min } & P_{3, \min }, \ldots \ldots, P_{n, \min }
\end{array}\right]
$$

Based on the above single dimensional matrix, a square matrix $(I)$ is developed to identify the economic schedule of generation. The formation of the square matrix is as follows. The process starts with a step increment in generation by $\Delta \mathrm{MW}$ in $P_{1, \min }$ by keeping the remaining units at its input value. This will form first row of the square matrix.

$$
I_{l}=\left[P_{1, \text { min }}+\Delta P_{2, \min } P_{3, \text { min }}, \ldots \ldots, P_{n, \text { min }}\right]
$$

The increment in generation is made in the second element by keeping the other elements at its input value that leads to the development of second row of the square matrix. 


$$
I_{2}=\left[P_{1, \min } P_{2, \min }+\Delta P_{3, \min }, \ldots \ldots ., P_{n, \min }\right]
$$

In the same logic, an increment is made for remaining units one at a time and a square matrix with a dimension equal to the number of units has been developed. For every step increment in the operating range of the plant the unit one at a time is allowed to experience the change in generation thus leads to the formation of the square matrix.

$$
I=\left[\begin{array}{l}
I_{1} \\
I_{2} \\
\cdot \\
I_{n}
\end{array}\right]=\left[\begin{array}{cccc}
P_{1, \text { min }}+\Delta & P_{2, \text { min }} & \ldots & P_{n, \min } \\
P_{1, \text { min }} & P_{2, \text { min }}+\Delta & \ldots & P_{n, \text { min }} \\
\cdot & \cdot & \cdot & \cdot \\
P_{l, \text { min }} & P_{2, \text { min }} & \ldots & P_{n, \text { min }}+\Delta
\end{array}\right]
$$

Each element in the square matrix represents the generation of a unit corresponding to the column that should satisfy the unit capacity constraints. In addition, the operational constraints such as ramp rate limits and prohibited operating zones are also enforced. The operating regions of the unit after including ramp rate limits are identified as mentioned in Equation (8). The operating regions of the units having prohibited operating zones are separated into isolated sub regions and it is identified using Equation (9). The operating regions of the units having prohibited operating zones and ramp rate constraints are obtained as mentioned earlier. The units are allowed to operate in the one of the operating zones. If the generation of a unit falls in a prohibited operating zone, the feasible optimal level would most likely to be located in any one of the adjacent feasible operating regions, that is, the operating region above or below the prohibited operating zone.

In the square matrix the unit generations of each row that satisfy the constraints are identified and total fuel cost of generation is evaluated. The desired economic schedule of generation is identified by analyzing fitness of each row. The fitness function of each row is calculated as,

$$
f i t(j)=\frac{F_{T}(j)}{(p d+\Delta)} j=1,2, \ldots n
$$

where, pd is the total of input values.

The schedule with the minimum fitness is chosen as the successive state input values. This process is repeated till all the generating units reach their maximum generation capacity. The feasible solutions for every increment from $P_{\min }$ to $P_{\max }$ are obtained and hence the best solution for any load demand falls in the operating boundary can be easily sited.

In practical applications, the total generation must be equal to the power demand and transmission loss. In such cases, the power balance constraint is exactly met by calculating the diagonal unit generation as follows.

$$
P_{i, i}=(p d+\Delta)+P_{L}-\sum_{\substack{j=l \\ j \neq i}}^{n} P_{i, j} \quad i=1,2, \ldots, n
$$

The detailed computational flow of the proposed method is presented in Figure 1. The proposed methodology in the form of matrix framework to support the demonstration is as follows.

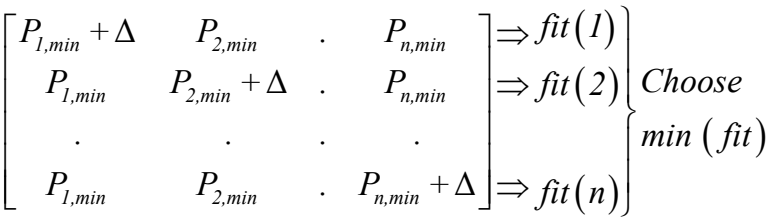

$$
\begin{aligned}
& \downarrow \\
& \text { Final Stage }
\end{aligned}
$$

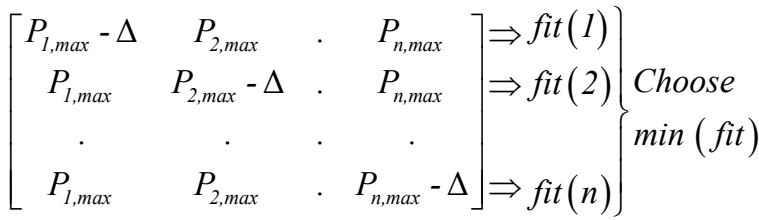

\section{Simulations Results and Discussions}

A simplified methodology based on sequential approach with matrix framework is developed for solving different kinds of economic dispatch problems. The effectiveness of this approach is tested for solving various kinds of economic dispatch problems including combined economic and emission dispatch problem, multi area economic dispatch problem and economic dispatch with multiple fuel options.

The algorithm for solving the examples were implemented in Matlab 7.0 platform and executed with Pentium IV, $2.8 \mathrm{GHz}$ personal computer. The proposed methodology provides the optimal schedule of generations for all possible load demands which is varied from minimum technical limit by a small increment to maximum technical limit of the system. The selection of increment is also an important factor. Too large increment may end up with unfeasible solution and too small increment may take long execution time. Based on experience, the desired increment is chosen as $1 \mathrm{MW}$.

\subsection{Case A: Economic Dispatch (ED) Problem with Generator Operating Constraints}

The objective is the minimization of total fuel cost subject to power balance and generator operational constraints. The effectiveness and efficiency of the developed approach is tested with large scale economic dis- 


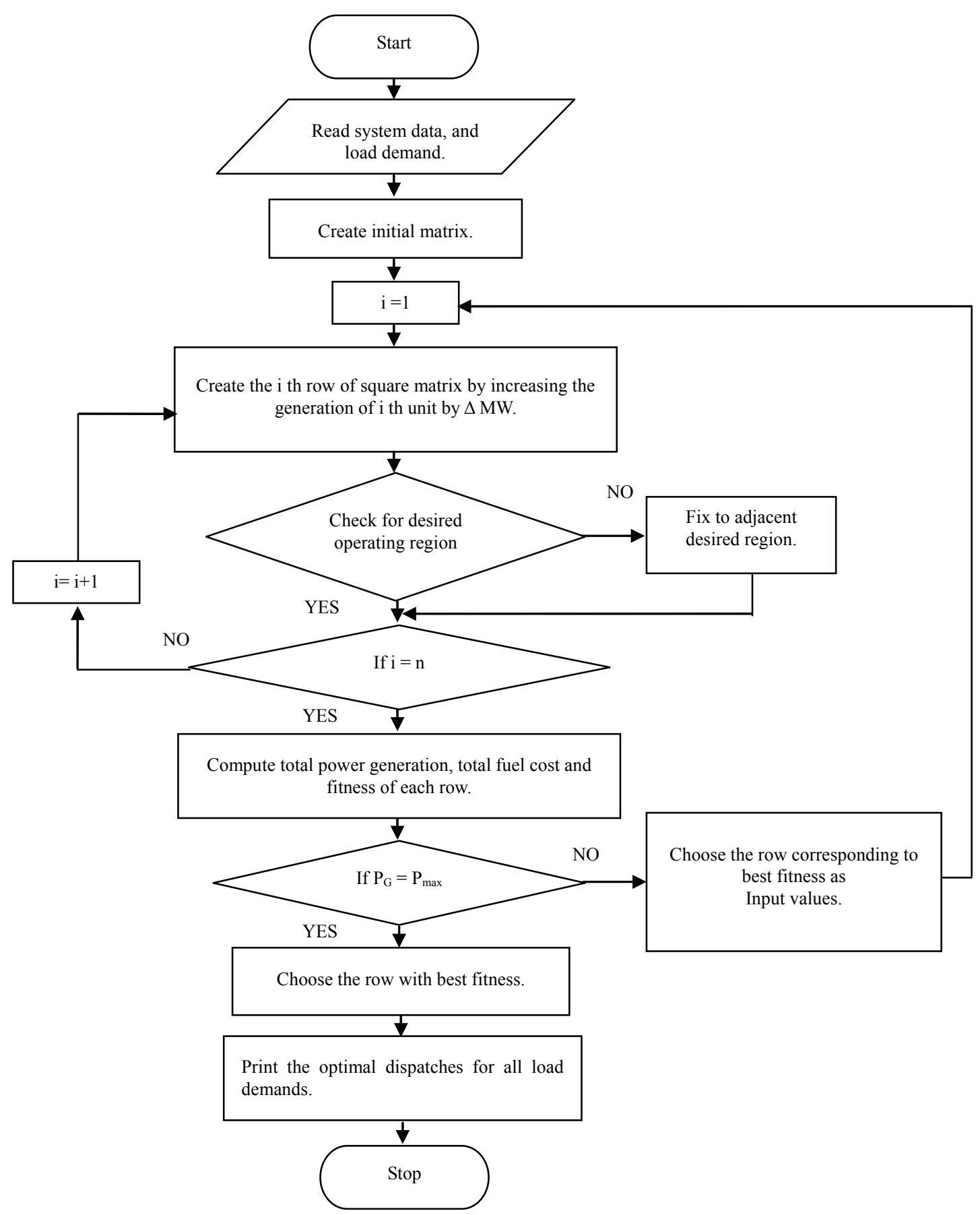

Figure 1. Computational flow of proposed method.

patch problem and economic dispatch problem with generator operational constraints. The 40 unit and 15 unit sample systems are considered for the case studies.

The first sample system consists of forty units in the realistic Taipower system that is a large scale and mixed -generating system where coal-fired, oil-fired, gas-fired, diesel and combined cycle are present. The cost coefficients and maximum and minimum generation limits of the sample system are available in literature [15]. The simulation results for load demands of $9000 \mathrm{MW}, 9500$ MW and 10500 MW are compared with Simulated Annealing (SA) [15], Genetic Algorithm (GA) [15], Hybrid Differential Evolution (HDE) [15], Variable Scaling Hybrid Differential Evolution (VSHDE) [15] and Direct Search Genetic Algorithm (DSGA) [17] and the comparison of results are presented in Table 1. As seen from comparison, the proposed method provides the minimum generation cost for above mentioned load demands. It 
Table 1. Total fuel cost (\$/h) comparison of 40 unit system.

\begin{tabular}{cccc}
\hline \multirow{2}{*}{ Method } & \multicolumn{3}{c}{ Load demand } \\
\cline { 2 - 4 } $\begin{array}{c}\text { Proposed } \\
\text { method }\end{array}$ & 121039.18 & 128219.31 & 143721.71 \\
$\begin{array}{c}\text { VSHDE } \\
\text { [15] }\end{array}$ & 121253.01 & --- & 143943.90 \\
HDE [15] & 121266.40 & --- & 143955.83 \\
GA [15] & 121839.72 & --- & 144486.02 \\
SA [15] & 135229.69 & --- & 164069.36 \\
DSGA [17] & --- & 128424.26 & --- \\
\hline
\end{tabular}

also clears that the proposed methodology is efficient to solve large scale economic dispatch problems.

The cost coefficients, maximum and minimum generation limits, ramp rate limits and prohibited operating zones and the transmission loss coefficients with a base capacity of 100 MVA of the fifteen unit sample system are reported in the literature [9]. The minimum and maximum technical limits of the system are $915 \mathrm{MW}$ and 3542 MW respectively. The operating regions of the unit are identified after incorporating ramp rate limits and prohibited operating zone constraints. The transmission loss is calculated using transmission loss matrix or B coefficients. The power balance is exactly met by evaluating the generation using Equation (23). The generations of the units neglecting transmission loss are treated as input values for the successive state. The optimum generations of individual thermal units and total fuel cost for the load demand of $2630 \mathrm{MW}$ are presented in Table 2. The simulation result is compared with GA [9], PSO [9], Modified PSO (MPSO) [18] and Adaptive Bacterial Foraging-Nelder Mead method (ABFNM) [19] and the comparison of results are presented in Table 3. It is clear from the comparison of results that the proposed method provides better schedule of generations to meet the load demand with existing techniques.

\subsection{Case B: Combined Economic and Emission Dispatch (CEED) Problem}

The objective of this multi objective optimization problem is to determine the optimal generations of thermal units by minimizing the total fuel cost and emission simultaneously subject to various system operating constraints. The price penalty factor multiobjective optimization problem can be converted into a single objective optimization problem. Various price penalty factors $[23$, $31,35]$ are suggested and among these maximum price penalty factor is chosen for combining cost of fuel plus the implied cost of emission as it offers a very good solution for emission restricted less cost condition [35]. In this article the maximum price penalty factor is considered. The maximum price penalty factor of each genera-
Table 2. Economic dispatch results for 15 unit system.

\begin{tabular}{cccccc}
\hline Unit & $\begin{array}{c}\text { Output } \\
(\mathrm{MW})\end{array}$ & Unit & $\begin{array}{c}\text { Output } \\
(\mathrm{MW})\end{array}$ & Unit & $\begin{array}{c}\text { Output } \\
(\mathrm{MW})\end{array}$ \\
\hline 1 & $\mathbf{4 5 5 . 0 0}$ & 6 & $\mathbf{4 6 0 . 0 0}$ & 11 & $\mathbf{8 0 . 0 0}$ \\
2 & $\mathbf{3 8 0 . 0 0}$ & 7 & $\mathbf{4 3 0 . 0 0}$ & 12 & $\mathbf{8 0 . 0 0}$ \\
3 & $\mathbf{1 3 0 . 0 0}$ & 8 & $\mathbf{6 0 . 0 0}$ & 13 & $\mathbf{2 5 . 0 0}$ \\
4 & $\mathbf{1 3 0 . 0 0}$ & 9 & $\mathbf{7 0 . 9 0 3 3}$ & 14 & $\mathbf{1 5 . 0 0}$ \\
5 & $\mathbf{1 7 0 . 0 0}$ & 10 & $\mathbf{1 5 9 . 0 0}$ & 15 & $\mathbf{1 5 . 0 0}$ \\
\hline \multicolumn{6}{c}{ Load demand $(\mathrm{MW})$} \\
\hline \multicolumn{6}{c}{ Transmission loss $(\mathrm{MW})$} \\
\hline
\end{tabular}

Table 3. Simulation results comparison for 15 unit system.

\begin{tabular}{ccc}
\hline \multirow{2}{*}{ Method } & \multicolumn{2}{c}{ Load demand $2630 \mathrm{~W}$} \\
\cline { 2 - 3 } & $\begin{array}{c}\text { Transmission loss } \\
(\mathrm{MW})\end{array}$ & Total fuel cost $(\$ / \mathrm{h})$ \\
\hline Proposed method & $\mathbf{2 9 . 9 0 3 3}$ & $\mathbf{3 2 6 9 6 . 8 1}$ \\
ABFNM [19] & 28.9470 & 32784.5024 \\
MPSO [18] & 30.908 & 32708 \\
PSO [9] & 32.431 & 32858 \\
GA [9] & 38.278 & 33113 \\
\hline
\end{tabular}

tor is the ratio between the fuel cost and emission at its maximum power output.

$$
h_{i, \text { max }}=\frac{\left(a_{i} P_{i, \text { max }}^{2}+b_{i} P_{i, \max }+c_{i}\right)}{\left(d_{i} P_{i, \text { max }}^{2}+e_{i} P_{i, \text { max }}+f_{i}\right)}
$$

The effectiveness of the proposed approach has been analyzed with 6 unit test system. The system details including cost coefficients, emission coefficients, minimum and maximum generation limits and transmission loss coefficients are given in [40]. The optimal dispatches are obtained for load demands vary from 345 MW to $1350 \mathrm{MW}$. The simulation results are compared with $\lambda$-iteration method [39], Quadratic Programming (QP) [31], Artificial Immune System (AIS) [39] and NSGA II-MADM [40] for a load demand of $700 \mathrm{MW}$. The comparison of total fuel cost, total emission and transmission loss is tabulated in Table 4. The comparison clearly indicates the significant reduction in fuel cost and transmission losses over earlier reports and the solution obtained by the proposed approach is close agreement with $\lambda$-iteration method.

For most of the load demands, the proposed method yields better results and they are in good agreement with the existing methods. The economic and environmental dispatch is conflicting multiobjective problem when the fuel cost increases the emission level decreases and hence in vice versa. As per the above statement, for some load conditions, there is a slight deviation in cost and emission with respect to the other existing methods.

\subsection{Case C: Multi Area Economic Dispatch (MAED) Problem}

The economic dispatch problem is extended to take into 
Table 4. Simulation results comparison of six-generator system.

\begin{tabular}{cccc}
\hline \multirow{2}{*}{ Method } & \multicolumn{3}{c}{ Load demand 700 MW } \\
\cline { 2 - 4 } & $\begin{array}{c}\text { Total fuel } \\
\text { cost }(\$ / \mathrm{h})\end{array}$ & $\begin{array}{c}\text { Total } \\
\text { emission } \\
(\mathrm{kg} / \mathrm{h})\end{array}$ & $\begin{array}{c}\text { Transmission } \\
\text { loss }(\mathrm{MW})\end{array}$ \\
\hline $\begin{array}{c}\lambda \text {-iteration } \\
{[39]}\end{array}$ & 37781 & 442 & 21.17 \\
QP [31] & 37488 & 439.7 & 17.054 \\
$\begin{array}{c}\text { AIS [39] } \\
\begin{array}{c}\text { NSGA } \\
\text { II-MADM } \\
\text { [40] }\end{array}\end{array}$ & 37344 & 438.1 & 16.91 \\
$\begin{array}{c}\text { Proposed } \\
\text { method }\end{array}$ & $\mathbf{3 7 1 6 6 . 7 3}$ & $\mathbf{4 5 3 . 4 4}$ & $\mathbf{1 7 . 6 4}$ \\
\hline
\end{tabular}

considerations of transmission capacity limits to ensure the security of the system. A two area system with four thermal generating units is considered to illustrate the effectiveness of the proposed approach. The system data are available in the literature [41]. The total load demand in area 1 and area 2 are $70 \%$ and $30 \%$ of total load demand respectively and these two areas are interconnected through transmission lines. Each area consists of two generating units and for the sake of comparison with earlier reports transmission losses are not considered. The line flow limits of $90 \mathrm{MW}, 120 \mathrm{MW}$ and $200 \mathrm{MW}$ are considered for the analysis. The optimum generations of individual units of each area for load demand of 1200 MW including transmission line limits are tabulated in Table 5.

The total generation of area 2 is greater than the total generation of area 1 that can export as much economical excess as power to area 1 to satisfy the requirement in area 1 without violating transmission line flow limits. The results obtained by this proposed methodology are

Table 5. Optimal generation results of two area system including transmission capacity constraints.

\begin{tabular}{ccccc}
\hline \multirow{2}{*}{ Load 1120 MW } & \multicolumn{3}{c}{ Flow limit (MW) } \\
\cline { 3 - 5 } & & $90 \mathrm{MW}$ & $90 \mathrm{MW}$ & $90 \mathrm{MW}$ \\
\hline $\begin{array}{c}\text { Optimal } \\
\text { generation } \\
\text { in area-1 }\end{array}$ & $\begin{array}{c}\mathrm{P} 1 \\
\mathrm{P} 2\end{array}$ & $\mathbf{5 2 8}$ & $\mathbf{5 0 6}$ & $\mathbf{4 4 5}$ \\
$(\mathrm{MW})$ & $\mathbf{1 6 6}$ & $\mathbf{1 5 8}$ & $\mathbf{1 3 9}$ \\
$\begin{array}{c}\text { Optimal } \\
\text { generation } \\
\text { in area-2 }\end{array}$ & $\begin{array}{c}\mathrm{P} 1 \\
(\mathrm{MW})\end{array}$ & $\mathbf{P} 2$ \\
$(\mathrm{MW})$ & $\mathbf{2 6 7}$ & $\mathbf{1 7 3}$ & $\mathbf{2 1 2}$ \\
\hline \multicolumn{2}{c}{ Total fuel cost $(\$ / \mathrm{h})$} & $\mathbf{1 0 7 0 0 . 8 0}$ & $\mathbf{1 0 6 6 9 . 0 9}$ & $\mathbf{1 0 6 0 4 . 6 8}$ \\
\hline
\end{tabular}

Table 6. Comparison of total fuel cost for MAED.

\begin{tabular}{|c|c|c|c|c|}
\hline \multirow{2}{*}{$\begin{array}{l}\text { Load } \\
\text { (MW) }\end{array}$} & \multirow{2}{*}{$\begin{array}{c}\text { Flow } \\
\text { limit } \\
(\mathrm{MW})\end{array}$} & \multicolumn{3}{|c|}{ Total generation cost $(\$ / \mathrm{h})$} \\
\hline & & $\begin{array}{c}\text { EDSM } \\
{[43]}\end{array}$ & NN [44] & $\begin{array}{c}\text { Proposed } \\
\text { method }\end{array}$ \\
\hline \multirow{3}{*}{800} & 90 & 7812.2 & 7812.2 & 7811.94 \\
\hline & 120 & 7791.5 & 7791.5 & 7791.25 \\
\hline & 200 & 7754.8 & 7754.8 & 7754.70 \\
\hline \multirow{3}{*}{1030} & 90 & 9874.7 & 9874.7 & 9874.20 \\
\hline & 120 & 9846.4 & 9846.4 & 9846.01 \\
\hline & 200 & 9789.7 & 9789.7 & 9789.42 \\
\hline \multirow{3}{*}{1120} & 90 & 10701 & 10701 & 10700.80 \\
\hline & 120 & 10670 & 10670 & 10669.09 \\
\hline & 200 & 10605 & 10605 & 10604.68 \\
\hline
\end{tabular}

compared with Economic Dispatch Direct Search Method (EDSM) [41] and Neural Network (NN) [42] and the comparison of results are presented in Table 6.

\subsection{Case D: Economic Dispatch Problem with Multiple Fuel Options (EDMFO)}

The economic dispatch problem with multiple fuel options has been solved in two phases. In first phase, the most economic fuel of each generating unit is identified. The economic dispatch of generating units is determined by a sequential approach with the selected fuels in second phase. The implementation procedure of the proposed methodology has been detailed as follows.

The primary search process calculates the composite cost function of each generating unit and the detailed derivation of composite cost coefficients are presented in Appendix. Then sequential approach with matrix framework is performed to identify the most economic fuel of each unit. The composite function and capacity of the units are using for the above process. This phase provides the generation dispatches and the fuel corresponding to the dispatches is known as the most economic fuel. The generation limits corresponding to the selected fuel is the desired operating region of the unit. At the end of first phase, the most economic fuel and the desired operating region of each unit are obtained. In second phase, the generation dispatches of the units are refined within the desired operating regions. The cost functions of the selected fuels are considered and sequential approach with matrix framework is performed again to obtain the optimal dispatches of generating units.

The effectiveness of this proposed approach for solving this problem is tested with a sample system consists of ten generating units, each unit with two or three fuel options. The details of fuel options, cost coefficients and maximum and minimum generations of each fuel in each generating unit are available in the literature [43]. The simulation result for load demand of $2700 \mathrm{MW}$ is de- 
tailed in Table 7. The total fuel cost for load demands of $2500 \mathrm{MW}, 2600 \mathrm{MW}$ and $2700 \mathrm{MW}$ obtained by this methodology, Hierarchical Method (HM) [43], Hopfield Neural Network (HNN) [44], Adaptive Hopfield Neural Network (AHNN) [45], Hybrid Genetic Algorithm (HGA) [46], Classical Evolutionary Programming (CEP) [47], Fast Evolutionary Programming (FEP) [47], Improved Fast Evolutionary Programming (IFEP) [47] and Particle Swarm Optimization [48] are compared and the comparison of results are detailed in Table 8. From the comparison of results, it is clear that the proposed approach provides comparable result for economic dispatch problem with piecewise quadratic function.

The computational time for the above case studies by the proposed approach is presented in Table 9.

The proposed methodology has following merits.

Table 7. Economic dispatch results of 10 unit system with multiple fuel options (Load=2700 MW).

\begin{tabular}{cccccc}
\hline Unit & $\begin{array}{c}\text { Fuel } \\
\text { type }\end{array}$ & $\begin{array}{c}\text { Generation } \\
(\mathrm{MW})\end{array}$ & Unit & $\begin{array}{c}\text { Fuel } \\
\text { type }\end{array}$ & $\begin{array}{c}\text { Generation } \\
(\mathrm{MW})\end{array}$ \\
\hline 1 & $\mathbf{2}$ & $\mathbf{2 1 8}$ & 6 & $\mathbf{3}$ & $\mathbf{2 4 0}$ \\
2 & $\mathbf{1}$ & $\mathbf{2 1 2}$ & 7 & $\mathbf{1}$ & $\mathbf{2 8 8}$ \\
3 & $\mathbf{1}$ & $\mathbf{2 8 1}$ & 8 & $\mathbf{3}$ & $\mathbf{2 4 0}$ \\
4 & $\mathbf{3}$ & $\mathbf{2 4 0}$ & 9 & $\mathbf{3}$ & $\mathbf{4 2 8}$ \\
5 & $\mathbf{1}$ & $\mathbf{2 7 8}$ & 10 & $\mathbf{1}$ & $\mathbf{2 7 5}$ \\
\hline & & & & $\mathbf{6 2 3 . 8 1}$ \\
\hline
\end{tabular}

Table 8. Comparison of total fuel cost for 10 unit system with multiple fuel options.

\begin{tabular}{cccc}
\hline \multirow{2}{*}{ Method } & \multicolumn{3}{c}{ Total fuel cost (\$/h) } \\
\cline { 2 - 4 } & $2500 \mathrm{MW}$ & $2600 \mathrm{MW}$ & $2700 \mathrm{MW}$ \\
\hline HM [43] & 526.70 & 574.03 & 625.18 \\
HNN [44] & 526.13 & 574.26 & 626.12 \\
AHNN [45] & 526.23 & 574.37 & 626.24 \\
HGA [46] & 526.24 & 574.38 & 623.81 \\
IFEP [47] & 526.25 & --- & --- \\
FEP [47] & 526.26 & --- & --- \\
CEP [47] & 526.25 & --- & --- \\
PSO [48] & --- & --- & 623.88 \\
$\begin{array}{c}\text { Proposed } \\
\text { method }\end{array}$ & $\mathbf{5 2 6 . 2 4}$ & $\mathbf{5 7 4 . 3 8}$ & $\mathbf{6 2 3 . 8 1}$ \\
\hline
\end{tabular}

Table 9. Total execution time for various case studies.

\begin{tabular}{ccc}
\hline Case study & Test system & Execution time (s) \\
\hline \multirow{2}{*}{ ED } & 40 Unit & 1.5337 \\
& 15 Unit & 0.6642 \\
CEED & 6 Unit & 0.2613 \\
MAED & Two area system & 0.2534 \\
EDMFO & 10 Unit & 0.2700 \\
\hline
\end{tabular}

- From these studies, this approach has the competence to solve various types of economic dispatch problem.

- It is a first method that provides the optimal solution for all possible load demands of system in a single run.

- It provides the schedule with minimum total cost in all cases hence global optimal solution.

- The performance of the proposed approach is independent of the number of generating units in the system and hence it is suitable for system of any size.

- The computational procedure is minimal.

- It offers the solution for all load demands of a system hence it takes a reasonable execution time.

\section{Conclusions}

This article presents sequential approach with matrix framework for solving various kinds of economic dispatch problems. The proposed methodology is validated by solving the different economic load dispatch problem such as large scale economic dispatch, economic dispatch with generator operating constraints, combined economic and emission dispatch, multiarea economic dispatch and economic dispatch with multiple fuel options. The different scale of power systems are considered in each case. The practical operational constraints of generators like ramp rate limits and prohibited operating zones are also taken into account for the solution of economic dispatch problems. The price penalty factor approach is used to convert the multi objective optimization problem into single objective optimization problem and maximum price penalty factor is considered as it offers very good solution for emission constrained less cost condition. The proposed approach is extended for solving economic dispatch problems with line flow constraints. Further, simple methodology for solving economic dispatch problem with multiple fuel options is presented. The most economic fuel of generating unit is identified by using the composite cost function and sequential approach with matrix frame work. These decentralized approaches provide simple solution methodology for economic dispatch problem with multiple fuel options. The simulation results of different case studies are compared with recent reports. The comparison of results concludes that the proposed methodology provides the minimum total fuel cost hence global optimal solution for various types of economic dispatch problems.

\section{Acknowledgements}

The authors gratefully acknowledge the management the support and facilities provided by the authorities of Annamalai University, Annamalainagar, India to carry out this research work. 


\section{References}

[1] A. J. Woods and B. F. Wollenberg, "Power Generation, Operation and Control," John Wiley \& Sons, New York, 1996.

[2] O. I. Elgerd, "Electric Energy Systems Theory, An introduction," 2nd Edition, McGraw Hill Book Company, New York, 1982.

[3] R. B. Adler and R. Fischal, "Security Constrained Economic Dispatch with Participation Factors Based on Worst Case Bus Load Violations," IEEE Transactions on Power Apparatus and Systems, Vol. 96, 1977, pp. 347356.

[4] R. T. Bui and S. Ghaderpanah, "Real Rescheduling and Security Assessment," IEEE Transactions on Power Apparatus and Systems, Vol. PAS-101, No. 8, 1982, pp. 2906-2915.

[5] K. P. Wong and C. C. Wang, "Simulated Annealing Based Economic Dispatch Algorithm," IEE Proceedings in Generation, Transmission and Distribution, Vol. 140, No. 6, 1993, pp. 509-515.

[6] S. O. Orero and M. R. Erving, "Economic Dispatch of Generators with Prohibited Operating Zones: A Genetic Algorithm Approach," IEE Proceedings in Generation, Transmission and Distribution, Vol. 143, No. 6, 1996, pp. 529-534.

[7] M. Djukanovic, M. Calovic, B. Milosevic and D. J. Sobejic, "Neural-Net Based Real Time Economic Dispatch for Thermal Power Plants," IEEE Transactions on Energy Conversion, Vol. 11, No. 4, 1996, pp. 755-761.

[8] R. Naresh, J. Dubey and J. Sharma, "Two-Phase Neural Network Based Modelling Framework of Constrained Economic Load Dispatch," IEE Proceedings in Generation, Transmission and Distribution, Vol. 151, No. 3, 2004, pp. 373-378.

[9] Z. L. Gaing, "Particle Swarm Optimization to Solving the Economic Dispatch Considering the Generator Constraints," IEEE Transactions on Power Systems, Vol. 18, No. 3, 2003, pp. 1187-1195.

[10] J.-B. Park, K.-S. Lee, J.-R. Shin and K. Y. Lee, "A Particle Swarm Optimization for Economic Dispatch with Non-Smooth Cost Function," IEEE Transactions on Power Systems, Vol. 20, No. 1, 2005, pp. 34-42.

[11] A. P. Neto, C. Unsihuay and O. R. Saveedra, "Efficient Evolutionary Strategy Optimization Procedure to Solve the Non-Convex Economic Dispatch Problem with Generator Constraints," IEE Proceedings on Generation Transmission and Distribution, Vol. 152, No. 5, 2005, pp. 653-660.

[12] W.-M. Lin, H.-J. Gow and M.-T. Tsay, "A Partition Approach Algorithm for Non-Convex Economic Dispatch," Electric Power and Energy Systems, Vol. 29, No. 5, 2007, pp. 432-438.

[13] A. Y. Abdelaziz, S. F. Mekhamer, M. A. L. Badr and M. Z. Kamz, "Economic Dispatch Using an Enhanced Hopfield Neural Network," Electric Power Components and Systems, Vol. 36, No. 7, 2008, pp. 719-732.
[14] N. Noman and H. Iba, "Differential Evolution for Economic Dispatch Problems," Electric Power Systems Research, Vol. 78, No. 8, 2008, pp. 1322-1331.

[15] J.-P. Chiou, "Variable Scaling Hybrid Differential Evolution for Large Scale Economic Dispatch Problems," Electric Power Systems Research, Vol. 77, No. 3-4, 2007, pp. 212-218.

[16] J. Cai, X. Ma, L. Li, Y. Yang, H. Peng and X. Wang, "Chaotic Ant Swarm Optimization to Economic Dispatch," Electric Power Systems Research, Vol. 77, No. 10, 2007, pp. 1373-1380.

[17] A. Theerthamalai and S. Maheswarapu, "Directional Search Genetic Algorithm Applications to Economic Dispatch of Thermal Units," International Journal of Computational Methods in Engineering Science and Mechanics, Vol. 9, No. 4, 2008, pp. 211-216.

[18] C. C. Kuo, "A Novel Coding Scheme for Practical Economic Dispatch by Modified Particle Swarm Approach," IEEE Transactions on Power Systems, Vol. 23, No. 4, 2008, pp. 1825-1835.

[19] B. K. Panigrahi and V. R. Pandi, "Bacterial Foraging Optimization: Nelder-Mead Hybrid Algorithm for Economic Load Dispatch," IET Generation, Transmission and Distribution, Vol. 2, No. 4, 2008, pp. 556-565.

[20] "Potential Impacts of Clean Air Regulations on System Operations," IEEE Current Operating Problems Working Group, Vol. 10, 1998, pp. 647-653.

[21] A. A. El-keib, H. Ma and J. L. Hart, "Environmentally Constrained Economic Dispatch Using a Lagrangian Relaxation Method," IEEE Transactions on Power Systems, Vol. 9, No. 4, 1994, pp. 1723-1729.

[22] M. W. Lamont and E. V. Qbessis, "Emission Dispatch Models and Algorithms for the 1990's," IEEE Transactions on Power Systems, Vol. 10, No. 2, 1995, pp. 941947.

[23] K. Srikrishna and C. Palanichamy, "Economic Thermal Power Dispatch with Emission Constraint," Journal of Institution of Engineers (India), Vol. 72, 1991, pp. 11-18.

[24] Y. H. Song, G. S. Wang, P. Y. Wang and A. T. Johns, "Environmental/Economic Dispatch Using Fuzzy Logic Controlled Genetic Algorithms," IEE Proceedings on Generation, Transmission and Distribution, Vol. 144, No. 4, 1997, pp. 377-382.

[25] G. Singh, S. C. Srivastava, P. K. Kalra and D. M. Vinoth Kumar, "Fast Approach to Artificial Neural Network Training and its Application to Economic Load Dispatch," Electrical Machines and Power Systems, Vol. 23, No. 1, 1995, pp. 13-24.

[26] C. T. Su and G. J. Chiou, "A Fast Computation Hopfield Method to Economic Load Dispatch of Power Systems," IEEE Transactions on Power Systems, Vol. 12, No. 4, 1997, pp. 1759-1764.

[27] C. M. Haung, H. T. Yang and C. L. Huang, "Bi-objective Power Dispatch Using Fuzzy Satisfaction-Maximizing Decision Approach," IEEE Transactions on Power Systems, Vol. 12, No. 4, 1997, pp. 1715-1721.

[28] P. K. Hota, R. Chakrabarti and P. K. Chattopadhyay, 
"Economic Emission Load Dispatch through an Interactive Fuzzy Satisfying Method," Electric Power Systems Research, Vol. 54, No. 3, 2000, pp. 151-157.

[29] K. P. Wong and J. Yuryevich, "Evolutionary Programming Based Algorithm for Environmentally Constrained Economic Dispatch," IEEE Transactions on Power Systems, Vol. 13, No. 2, 1998, pp. 301-309.

[30] P. Venkatesh, R. Gnanadass and N. P. Padhy, "Comparison and Application of Evolutionary Programming Techniques to Combined Economic Emission Dispatch with Line Flow Constraints," IEEE Transactions on Power Systems, Vol. 18, No. 2, 2003, pp. 688-697.

[31] R. M. S. Danaraj and F. Gajendran, "Quadratic Programming Solution to Emission and Economic Dispatch Problems," Journal of Institution of Engineers (India), Vol. 86, 2005, pp. 129-132.

[32] S. Muralidharan, K. Srikrishna and S. Subramanian, "Emission Constrained Economic Dispatch-A New Recursive Approach," Electric Power Components and Systems, Vol. 34, No. 3, 2006, pp. 343-353.

[33] L. F. Wang and C. Singh, "Environmental/Economic Power Dispatch Using a Fuzzified Multi-Objective Particle Swarm Optimization Algorithm," Electric Power Systems Research, Vol. 77, No. 12, 2007, pp. 1654-1664.

[34] J. S. AL-Sumait, J. K. Sykulski and A. K. L-Othman, "Solution of Different Types of Economic Dispatch Problems Using Pattern Search Method," Electric Power Components and Systems, Vol. 36, No. 3, 2008, pp. 250265.

[35] R. Balamurugan and S. Subramanian, "A Simplified Recursive Approach to Combined Economic Emission Dispatch," Electric Power Components and Systems, Vol. 36, No. 1, 2008, pp. 17-27.

[36] C. Palanichamy and N. S. Babu, "Analytical Solution for Combined Economic and Emissions Dispatch," Electric Power Systems Research, Vol. 78, No. 7, 2008, pp. 11291137.

[37] K. T. Chaturvedi, M. Pandit and L. Srivstava, "Modified Neo-Fuzzy Neuron Based Approach for Economic and Environmental Optimal Power Dispatch," Applied Soft Computing, Vol. 8, No. 4, 2008, pp. 1428-1438.

[38] S. Agrawal, B. K. Panigrahi and M. K. Tiwari, "MultiObjective Particle Swarm Algorithm with Fuzzy Clustering for Electrical Power Dispatch," IEEE Transactions on
Evolutionary Computation, Vol. 12, No. 15, 2008, pp. 529-541.

[39] R. Geetha, R. Bhuvaneswari and S. Subramanian, "Artificial Immune System Based Combined Economic and Emission Dispatch," Proceedings of IEEE TENCON, IEEE Region 10 conference, Hyderabad, 2008.

[40] X. B. Li, "Study of Multi-Objective Optimization and Multi-Attribute Decision-Making for Economic and Environmental Power Dispatch," Electric Power Systems Research, Vol. 79, No. 5, 2009, pp. 789-795.

[41] C. L. Chen and N. Chen, "Direct Search Method for Solving Economic Dispatch Problem Considering Transmission Capacity Constraints," IEEE Transactions on Power Systems, Vol. 16, No. 4, 2001, pp. 764-769.

[42] T. Yalcinoz and M. J. Short, "Neural Networks Approach for Solving Economic Dispatch Problem with Transmission Capacity Constraints," IEEE Transactions on Power Systems, Vol. 13, No. 2, 1998, pp. 307-313.

[43] C. E. Lin and G. L. Viviani, "Hierarchical Economic Dispatch for Piecewise Quadratic Cost Functions," IEEE Transactions on Power Apparatus and Systems, Vol. PAS -103, No. 6, 1984, pp. 1170-1175.

[44] J. H. Park, Y. S. Kim, I. K. Eom and K. Y. Lee, "Economic Load Dispatch for Piecewise Quadratic Cost Function using Hopfield Neural Network," IEEE Transactions on Power Systems, Vol. 8, No. 3, 1993, pp. 1030-1038.

[45] K. Y. Lee, A. S. Yome and J. H. Park, "Adaptive Hopfield Neural Networks for Economic Load Dispatch," IEEE Transactions on Power Systems, Vol. 13, No. 2, 1998, pp. 519-526.

[46] S. Baskar, P. Subbaraj and M. V. C. Rao, "Hybrid Genetic Algorithm Solution to Economic Dispatch Problem with Multiple Fuel Options," Journal of Institution of Engineers (India), Vol. 82, 2001, pp. 177-183.

[47] T. Jayabarathi, K. Jayaprakash, D. N. Jayakumar and T. Raghunathan, "Evolutionary Programming Techniques for Different Kinds of Economic Dispatch Problems," Electric Power Systems Research, Vol. 73, No. 2, 2005, pp. 169-176.

[48] D. N. Jeyakumar, T. Jayabharathi and T. Raghunathan, "Particle Swarm Optimization for Various Types of Economic Dispatch Problems," Electric Power and Energy Systems, Vol. 28, No. 1, 2006, pp. 36-42. 


\section{Nomenclature}

$\begin{array}{ll}a_{i}, b_{i}, c_{i} & \text { Cost coefficients of generating unit } \mathrm{i} \\ d_{i}, e_{i}, f_{i} & \text { Emission coefficients of generating unit } \mathrm{i} \\ B_{i j}, B_{0 i}, B_{00} & \text { Transmission loss coefficients or B coef- }\end{array}$ ficients

$$
\begin{array}{cc}
E_{T} & \text { Total emission of generators in }(\mathrm{kg} / \mathrm{h}) \\
F_{T} & \text { Total operating cost or total fuel cost of } \\
\text { generation in }(\$ / \mathrm{h})
\end{array}
$$

$n \quad$ Number of generating units

$n_{i} \quad$ Number of prohibited operating zones

$P_{i} \quad$ Real power generation of generating unit

i in MW

$P_{i, \text { min }} \quad$ Minimum value of real power allowed at generator i in MW

$P_{i, \max }$ Maximum value of real power allowed at generator $\mathrm{i}$ in $\mathrm{MW}$

$P_{D} \quad$ Total load demand of the system in MW

$P_{L} \quad$ Total transmission losses in MW

$P_{i}^{0} \quad$ Output power of generator $\mathrm{i}$ before dispatched hour in MW

$P_{i, j}^{l} \quad$ Lower bound of generation of unit $i$ in prohibited operating zone $\mathrm{j}$ in MW

$P_{i, j}{ }^{u} \quad$ Upper bound of generation of unit $\mathrm{i}$ in prohibited operating zone $\mathrm{j}$ in MW

$U R_{i} \quad \mathrm{Up}$ ramp limit of $\mathrm{i}$ th generator in $(\mathrm{MW} / \mathrm{h})$

$D R_{i} \quad$ Down ramp limit of $\mathrm{i}$ th generator in $(\mathrm{MW} / \mathrm{h})$

$h$
$h_{i, \max }$

$(\$ / \mathrm{kg})$

$M$

system

$N_{m}$ an $\mathrm{M}$ area system

$a_{m n}, b_{m n}, c_{m n}$ Cost coefficients of generating unit $\mathrm{n}$ in area $\mathrm{m}$

$P_{m n}$

MW

$P_{D m} \quad$ Load demand for area $\mathrm{m}$ in MW

$t_{j k} \quad$ Economic tie transfer from area $\mathrm{j}$ to $\mathrm{k}$ in

MW

$t_{j k, \min ,} t_{j k, \max }$ Tie line minimum and maximum capacity limits in MW

$\beta_{m} \quad$ Set of tie lines in area $\mathrm{m}$

$s \quad$ One dimensional matrix consists of input

values

I Square matrix consists of real power generations of units

fit Fitness of the solution in (\$/MWh)

$P_{\min } \quad$ Minimum technical limit in MW

$P_{\max } \quad$ Maximum technical limit in MW

\section{Appendix}

The incremental production cost of a plant is a prior re- quirement for coordination among plants. The incremental production cost of the plant can be derived by a simple realignment of the fuel cost coefficients of the units. Consider an " $n$ " unit system and the cost equation of $\mathrm{n}$ th unit is,

$$
F_{n}=a_{n} P_{n}^{2}+b_{n} P_{n}+c_{n}
$$

and the composite cost function of the plant can be written as,

$$
F_{T}=A P_{G}^{2}+B P_{G}+C
$$

The composite cost coefficients are derived as follows. The total fuel cost $(\$ / h)$ of the "n" unit system can be written as,

$$
F_{T}=F_{1}+F_{2}+F_{3}+\ldots . .+F_{n}
$$

For most economical generation,

$$
\begin{array}{lcr}
2 a_{1} P_{1}+b_{1}=\lambda & ; & P_{1}=\left(\lambda-b_{1}\right) / 2 a_{1} \\
2 a_{n} P_{n}+b_{n}=\lambda & ; & P_{n}=\left(\lambda-b_{n}\right) / 2 a_{n} \\
---------------------- \\
2 A P_{G}+B=\lambda \quad ; & P_{G}=(\lambda-B) / 2 A
\end{array}
$$

where, $\lambda$ is the incremental production cost of the plant in MW.

The total generation of the plant can be written as,

$$
\begin{gathered}
P_{G}=P_{1}+P_{2}+P_{3}+\ldots .+P_{n} \\
P_{G}=\left[(\lambda / 2)\left(1 / a_{1}+1 / a_{2}+1 / a_{3}+\ldots+1 / a_{n}\right)\right] \\
-\left[(1 / 2)\left(b_{1} / a_{1}+b_{2} / a_{2}+b_{3} / a_{3}+\ldots+b_{n} / a_{n}\right)\right] \\
\lambda=2\left[1 /\left(1 / a_{1}+1 / a_{2}+1 / a_{3}+\ldots+1 / a_{n}\right)\right] P_{G} \\
+\left(b_{1} / a_{1}+b_{2} / a_{2}+b_{3} / a_{3}+\ldots+b_{n} / a_{n}\right) \\
{\left[1 /\left(1 / a_{1}+1 / a_{2}+1 / a_{3}+\ldots+1 / a_{n}\right)\right]}
\end{gathered}
$$

By comparing (A.4) and (A.5),

$$
\begin{aligned}
& A=1 /\left(1 / a_{1}+1 / a_{2}+1 / a_{3}+\ldots .+1 / a_{n}\right) \\
& B=\left(b_{1} / a_{1}+b_{2} / a_{2}+b_{3} / a_{3}+\ldots .+b_{n} / a_{n}\right) A
\end{aligned}
$$

The fuel cost can be rewritten as,

$$
\begin{aligned}
& F_{n}=\lambda^{2} / 4 a_{n}-b_{n}^{2} / 4 a_{n}+c_{n} ; \\
& F_{T}=\lambda^{2} / 4 A-B^{2} / 4 A+C ;
\end{aligned}
$$

From (A.8),

$$
\begin{aligned}
C= & \left(c_{1}+c_{2}+c_{3}+\ldots+c_{n}\right) \\
& \left(b_{1}^{2} / 4 a_{1}+b_{2}^{2} / 4 a_{2}+b_{3}^{2} / 4 a_{3}+\ldots+b_{n}^{2} / 4 a_{n}\right) \\
& +B^{2} / 4 A
\end{aligned}
$$

